\title{
Effect of chronic renal failure on the hepatic, intestinal, and renal expression
}

\section{of bile acid transporters}

\author{
Zhibo Gai, ${ }^{1 *}$ Lei Chu, ${ }^{2,3 *}$ Christian Hiller, ${ }^{1}$ Denis Arsenijevic, ${ }^{4}$ Carlos A. Penno, ${ }^{5}$ Jean-Pierre Montani, ${ }^{4}$ \\ Alex Odermatt, ${ }^{5}$ and Gerd A. Kullak-Ublick ${ }^{1}$ \\ ${ }^{1}$ Department of Clinical Pharmacology and Toxicology, University Hospital Zurich, Zurich, Switzerland; ${ }^{2}$ Minimally Invasive \\ Urology Center, Provincial Hospital Affiliated to Shandong University, Shandong, China; ${ }^{3}$ Tengzhou Central People's \\ Hospital, Shandong, China; ${ }^{4}$ Division of Physiology, Department of Medicine, University of Fribourg, Fribourg, Switzerland; \\ and ${ }^{5}$ Division of Molecular and Systems Toxicology, Department of Pharmaceutical Sciences, University of Basel, \\ Basel, Switzerland
}

Gai Z, Chu L, Hiller C, Arsenijevic D, Penno CA, Montani J, Odermatt A, Kullak-Ublick GA. Effect of chronic renal failure on the hepatic, intestinal, and renal expression of bile acid transporters. Am J Physiol Renal Physiol 306: F130-F137, 2014. First published November 6, 2013; doi:10.1152/ajprenal.00114.2013._Although the kidney is believed to play a minor role in bile acid (BA) excretion, chronic renal failure (CRF) has been reported to be associated with increased serum bile acid levels and alterations in BA homeostasis. The mechanisms for elevated BA levels are poorly understood in both clinical and experimental studies. This study was designed to examine the effects of naturally progressing CRF of longer duration on the hepatic and renal mRNA and protein levels of the BA-synthesizing enzyme Cyp7a1 and the BA transporters Ntcp, Bsep, Mrp3, Ost- $\alpha$, and Ost- $\beta$. Sprague-Dawley rats were randomized to the CRF group ( $5 / 6$ nephrectomy) or to the sham-operated control group and were analyzed 8 wk after surgery. Results obtained in the CRF rats were compared with those obtained in rats that had undergone uninephrectomy (UNX). The CRF group exhibited significantly increased plasma cholesterol and BA concentrations. Hepatic Cyp7a1 mRNA and protein levels were almost identical in the two groups. Hepatic Mrp3, Ost- $\alpha$, and Ost- $\beta$ expression was increased, suggesting increased basolateral efflux of bile acids into the blood. However, no such changes in BA transporter expression were observed in the remnant kidney. In UNX rats, similar changes in plasma BA levels and in the expression of BA transporters were found. We hypothesize that the increase in plasma BA is an early event in the progression of CRF and is caused by increased efflux across the basolateral hepatocyte membrane.

chronic renal failure; bile acid transporter; liver

THE KIDNEY IS ONE OF THE MAJOR organs involved in whole-body homeostasis, with its major functions being the excretion of waste metabolites, regulation of blood pressure and lipid metabolism, secretion and degradation of hormones, and the production and utilization of systemic glucose $(16,22,30)$. It is well known that chronic renal impairment is further complicated by high blood pressure (3), deranged carbohydrate metabolism (21), and dyslipidemia (5). Moreover, chronic renal failure (CRF) has been reported to be associated with increased serum bile acid levels and alterations in the bile acid balance (14).

* Z. Gai and L. Chu contributed equally to this work.

Address for reprint requests and other correspondence: G. A. Kullak-Ublick, Dept. of Clinical Pharmacology and Toxicology, Univ. Hospital Zurich, Rämistrasse 100, CH-8091 Zurich, Switzerland (e-mail: gerd.kullak@usz.ch).
Primary bile acids are synthesized from cholesterol by hepatocytes $(12,36)$. They are secreted into bile and play important roles in the emulsion, digestion, and absorption of dietary fat and liposoluble vitamins. Except for a small fraction of bile acids constituting $\sim 5 \%$ of the whole pool that is lost every day in the feces, the remaining bile acids that reach the intestine are actively reabsorbed toward the portal blood, mainly by the ileum (39). The flux of bile acid molecules through hepatocytes plays an important role in controlling, at the transcriptional level, the rate of metabolic pathways responsible for de novo biosynthesis of the additional bile acids necessary to compensate for fecal loss (25). Although it has traditionally been thought that filtration, reabsorption, and secretion by the kidney play a minor role in bile acid homeostasis in healthy humans, urinary output of sulfated bile acids becomes an important excretion route under cholestatic conditions $(9,37)$.

Several studies have reported that hepatic Cyp7a1 activity, the rate-limiting enzyme in bile acid synthesis, is virtually identical in rats with CRF and normal control animals $(19,34)$. Moreover, an unchanged rate of bile acid production was also demonstrated $(19,26)$, indicating normal hepatic de novo synthesis of bile acids in CRF. However, these studies did not evaluate expression of bile acid transporters. Thus, they could not explain the occurrence of elevated serum bile acid levels in $\mathrm{CRF}$. The present study was therefore undertaken to determine the mechanism underlying the increased bile acid levels in CRF. The expression of hepatic Cyp7a1 and of both hepatic and renal bile salt transporters (e.g., Ntcp, Slco1a1, Bsep, Mrp3, Mrp4, Ost- $\alpha$ and Ost- $\beta$ ) was compared in CRF and sham-operated control animals (with free access to regular rat chow). Furthermore, an additional uninephrectomized rat group was examined to study the impact of renal function on bile acid metabolism and transport.

\section{METHODS}

Animal models. Male Sprague-Dawley rats weighing 180-200 g were randomly assigned to the CRF and sham-operated normal control groups. Another group of male Sprague-Dawley rats weighing $180-200 \mathrm{~g}$ were randomly assigned to the UNX or sham-operated normal control groups. Rats from each group were housed in a climate-controlled, light-regulated facility with a 12:12-h day-night cycle. The animals were fed regular rat chow and received water ad libitum. The animals assigned to the renal surgery groups underwent a $5 / 6$ nephrectomy or a uninephrectomy by surgical resection using a flank incision to expose the kidney retroperitoneally as described 
elsewhere (42). Sham-operated animals underwent the same incision and kidney exposure, but the kidney was left intact. A minimum of eight animals was used in each group. Plasma total cholesterol and creatinine concentrations were measured using a synchro CX3 autoanalyzer (Beckman Instruments). Plasma total bile acids were measured using a kit from Crystal Chemistry, and individual bile acid species were quantitated by liquid chromatography-tandem mass spectrometry (LC-MS/MS) (27). Urinary protein concentrations were determined using a kit from Wako Chemical Industries (Tokyo, Japan). All experiments were approved by the local institutional animal committee.

Isolation of primary proximal tubule cells. Primary proximal tubule cells were isolated from kidneys of Sprague-Dawley rats as described previously (6). Briefly, kidney cortices from rats (weighing 180-200 g) were dissected, sliced, minced, and digested in $0.25 \%$ trypsin solution (Life Technologies BRL, Grand Island, NY) in a shaking incubator at $37^{\circ} \mathrm{C}$ for $1 \mathrm{~h}$. Trypsin was neutralized with growth medium (DMEM and 10\% FBS containing $100 \mathrm{U} / \mathrm{ml}$ penicillin and $0.1 \mathrm{mg} / \mathrm{ml}$ streptomycin). The suspension was pipetted and was passed through a $100-\mu \mathrm{m}$ cell strainer (BectonDickinson Labware, Franklin Lakes, NJ). The samples were centrifuged $(600 \mathrm{rpm}$ for 5 $\mathrm{min}$ ) to pellet the tubules, washed with $10 \mathrm{ml}$ of medium, centrifuged, and washed twice more. The final pellet, consisting mostly of renal tubules, was resuspended in culture medium (REBM bullet kit, Clonetics), plated onto culture dishes (Nalge Nunc, Naperville, IL), and incubated at $37^{\circ} \mathrm{C}$ in a $\mathrm{CO}_{2}$ incubator with medium changes every 2 days until confluent. Experiments were carried out in serum-free DMEM. Cells were incubated by the addition of $100 \mu \mathrm{M}$ chenodeoxycholic acid or $1 \mu$ M GW4064 (Sigma-Aldrich, St. Louis, MO) for $24 \mathrm{~h}$. Total RNA was extracted by the method described below.

Isolation of liver and kidney RNA and quantification of transcript levels. The rats were killed $8 \mathrm{wk}$ after surgery. The liver and kidney were removed immediately, snap frozen in liquid nitrogen, and stored at $-80^{\circ} \mathrm{C}$. Total RNA was prepared using TRIzol (Invitrogen). The amount of mRNA was determined from the absorbance at $260 \mathrm{~nm}$. After DNAse treatment (Promega), $2 \mu \mathrm{g}$ total RNA was reverse transcribed using oligo-dT priming and SuperscriptII (Invitrogen). First-strand complementary DNA was used as the template for realtime polymerase chain reaction analysis with TaqMan master mix and primers (Applied Biosystems). Transcript levels, determined in two independent complementary DNA preparations, were calculated as described and expressed relative to the GAPDH housekeeping gene. All of the results are expressed as means \pm SE. Unpaired $t$-tests were used for statistical comparisons.

Western blotting. Lysates (20 $\mu \mathrm{g}$ protein) from liver, ileum, or kidney tissue were separated by SDS-PAGE and blotted on polyvinylidene difluoride membranes (Millipore, Billerica, MA). The membranes were blocked with TBS containing $0.1 \%$ Tween 20 and $3 \%$ BSA for $1 \mathrm{~h}$ at room temperature and incubated overnight at $4^{\circ} \mathrm{C}$ with the respective antibodies. Subsequently, the blots were washed with TBS containing $0.1 \%$ Tween 20 , treated with horseradish-peroxidaseconjugated secondary antibodies at room temperature for $1 \mathrm{~h}$, and developed using the ECL Plus detection system (Amersham Bioscience, Buckinghamshire, UK). Antibodies against Bsep, Ntcp, Slco1a1, Mrp2, and Mrp3 were previously generated in our group (Dr. Bruno Stieger); anti-Cyp7a1 was from Biorbyt, anti-Ost $\alpha$, and anti-Asbt (Santa Cruz Biotechnology, Santa Cruz, CA).

\section{RESULTS}

Plasma bile acid concentrations in CRF rats. The effect of CRF on plasma cholesterol, creatinine, creatinine clearance, urinary protein, and body weight is shown in Table 1. As expected, the CRF group exhibited a significant increase in plasma creatinine concentration and a significant decrease in creatinine clearance and body weight compared with the nor-
Table 1. Effect of CRF on plasma concentrations of cholesterol, creatinine, creatinine clearance $(\mathrm{Ccr})$, urinary protein, and body weight

\begin{tabular}{lccc}
\hline \hline & Sham $(n=8)$ & CRF $(n=8)$ & $P$ Value \\
\hline Total cholesterol, mg/dl & $59.8 \pm 5.4$ & $142.5 \pm 16.4$ & $<0.01$ \\
Creatinine, ml/dl & $0.54 \pm 0.02$ & $1.31 \pm 0.16$ & $<0.01$ \\
Ccr, ml/24 h & $1.9 \pm 0.08$ & $0.6 \pm 0.11$ & $<0.01$ \\
Urine protein, $\mathrm{mg} / 24 \mathrm{~h}$ & $9.2 \pm 1.2$ & $39.2 \pm 3.4$ & $<0.01$ \\
Body weight, g & $433.5 \pm 6.9$ & $386.4 \pm 7.7$ & $<0.01$ \\
\hline
\end{tabular}

Values are means \pm SE; $n=8$ /group. Sham, sham-operated control; CRF, chronic renal failure; $\mathrm{Ccr}$, creatinine clearance.

mal control group. In addition, the CRF group exhibited mild proteinuria and a significant rise in total cholesterol relative to that found in the control group. In parallel, the plasma total bile acid concentration was significantly higher in the CRF group $(P<0.01$, Fig. $1 A)$, consistent with other reports $(11,14)$. The increase in plasma bile acids as determined with the enzymatic assay was confirmed by LC-MS/MS analysis of individual bile acid species, which showed about a twofold increase in the concentration of individual bile acids measured, notably unconjugated bile acids (Supplementary Table S1; all supplementary material for this article is accessible on the journal website.). Concentrations of almost all bile acids were increased in CRF rats, including cholic acid, chenodeoxycholic acid, muricholic acid, and hyodeoxycholic acid. However, the percentage of 6-hydroxylated bile acids (muricholic acid and hyodeoxycholic acid) did not differ between groups.

Effect of CRF on expression of bile acid transporters in the liver, intestine, and kidney. In view of the increase in serum bile acids, we studied the expression of hepatic Cyp7a1, the rate-limiting step in bile acid synthesis. As shown in Fig. 1, $C$ and $D$, expression of Cyp7a1 did not differ between the two groups at the mRNA and protein levels. Moreover, mRNA expression of Cyp8b1, an enzyme involved in the synthesis of cholic acid, was almost identical in the CRF group and control animals (Fig. 1B). These results indicate that the increase in plasma bile acids does not result from a higher synthesis rate of bile acids.

In CRF rats, both mRNA and protein expression of the basolateral uptake transporters Ntcp and Slcola1 did not differ compared with controls. In contrast, mRNA levels of Mrp3, Ost- $\alpha$, and Ost- $\beta$, the basolateral bile acid efflux transporters, were increased (Fig. 2A). Western blots confirmed higher expression of Mrp3 and Ost- $\alpha$ (Fig. 2B) in CRF rats at the protein level. However, mRNA expression of Bsep and Mrp2, the canalicular efflux pumps, was almost the same as in the sham group. Since Mrp3, Ost- $\alpha$, and Ost- $\beta$ are target genes of Fxr (43), a nuclear receptor that is activated by bile acids, we compared Fxr and its downstream target gene Shp in CRF and control groups. As shown in Fig. 2C, mRNA levels of Fxr and Shp did not differ between groups. Shp expression in CRF rats was consistent with that of Cyp7a1, indicating that elevated plasma bile acids do not negatively regulate bile acid synthesis in $\mathrm{CRF}$.

mRNA and protein levels of bile acid transporters from ileum and the remaining kidney of CRF rats were examined and compared with the control animals. In contrast to the changes in bile acid transporter expression found in the liver, there were no significant changes in bile acid transporters both 
Fig. 1. Effect of chronic renal failure (CRF) on total serum bile acid levels and bile acidsynthesizing enzymes in the liver. A: plasma total bile acid levels in control (sham) rats and rats with CRF. $B$ and $C$ : comparisons of hepatic Cyp8b1 mRNA $(B)$ and Cyp7a1 mRNA $(C)$ levels between sham and CRF groups. Values are means $\pm \mathrm{SE} ; n=$ 8/group. $D$ : representative Western blot of Cyp7a1 in liver tissue of sham and CRF groups. Samples from rat ileum were used as a negative control.
A

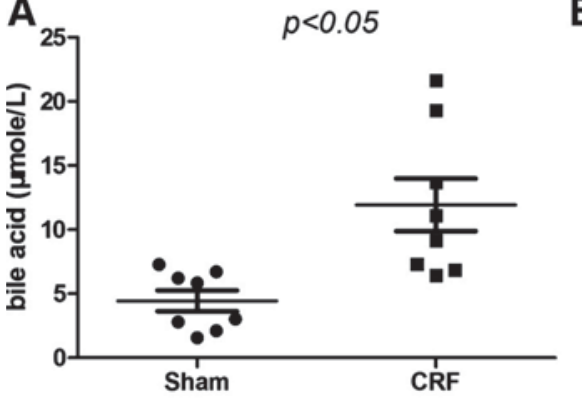

C

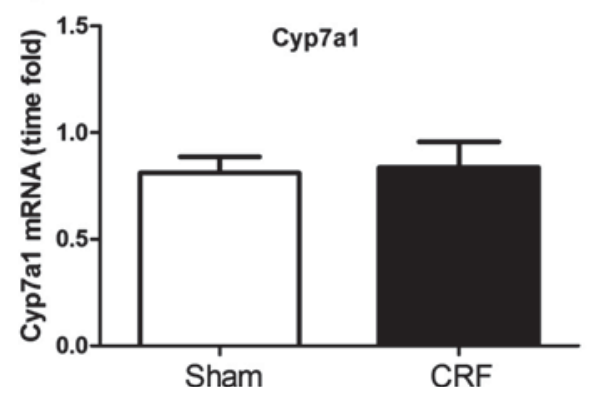

B

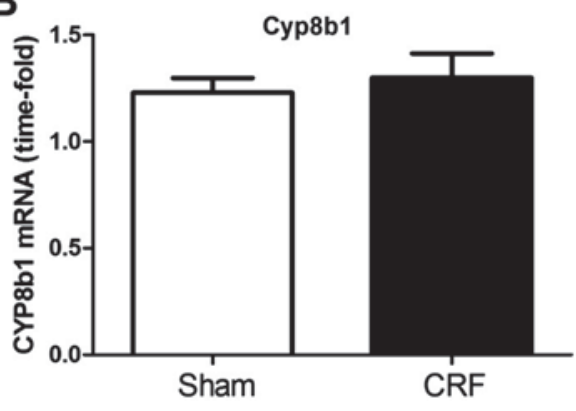

D

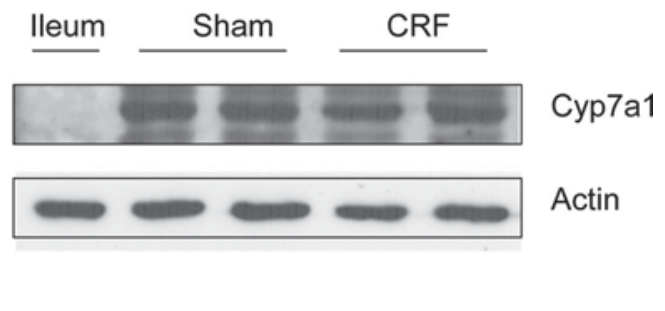

in the ileum and the remaining 1/6 kidneys of the CRF group (Fig. 3). Fxr and Shp levels in the kidney were also checked in both groups. Almost identical Fxr and Shp mRNA levels were found in the CRF group, indicating that the Fxr signaling pathway was not activated in the remaining kidney.

Effect of FXR agonists on expression of FXR target genes in proximal tubule cells from the kidney. In view of the apparent difference between the liver and kidney in the changes in bile acid transporter expression induced by CRF, we next investigated whether Fxr signaling is conserved in rat kidney. As Fxr is expressed in kidney proximal tubules (23) and many Fxr target genes are also located there (43), we aimed to exclude an absence of intact Fxr signaling in the kidney as an explanation for the lack of effect of CRF on renal bile acid transporter expression. To demonstrate this, we cultured kidney proximal tubule cells from rats and incubated cells with CDCA or GW4064, two Fxr agonists that activate Fxr signaling. Significant increases in Shp and Mrp2 mRNAs, two known Fxr target genes in the kidney $(8,15)$, were observed in proximal tubule cells incubated with CDCA or GW4064 for $24 \mathrm{~h}$. Meanwhile, the Fxr mRNA expression level did not change (Fig. 4). Furthermore, mRNA levels of bile acid transporters Ost- $\alpha / \beta$ were significantly higher, and the Slcola1 mRNA level was decreased after CDCA and GW4064 treatment (Fig. 4). Taken together, these data suggest that the Fxr signaling pathway is conserved in the kidney and that an activation of Fxr would be expected to influence the expression of bile acid transporters in renal proximal tubule cells.

Effect of UNX on bile acid transporters in the liver and kidney. Finally, we employed UNX as a model to further assess whether the change in bile acid levels was correlated with kidney function, since UNX rats did not show any renal failure at $8 \mathrm{wk}$ after surgery. As shown in Fig. $5 A$, increased plasma bile acid levels were also observed in UNX rats, with no marked changes in Cyp7a1 compared with the control group (Fig. 5C). Furthermore, hepatic basolateral bile acid transporters Ost- $\alpha / \beta$ were increased at the mRNA level (Fig. $5 B$ ).
However, analysis of the renal expression of bile acid transporters in the remnant kidney again showed no differences between the two groups (Fig. $5 D$ ).

\section{DISCUSSION}

This study shows that plasma bile acid levels are increased in rats with CRF induced by $5 / 6$ subtotal nephrectomy. We observed increased expression of hepatic basolateral bile acid efflux transporters Mrp3, Ost- $\alpha$, and Ost- $\beta$ in CRF rats, but no such changes in bile acid transporter expression were observed in ileum and the remnant kidney. Although the expression of Mrp3 and Ost- $\alpha / \beta$ is low in rodent liver, their mRNA levels were strongly increased in the liver of CRF rats, with no change in Shp and bile acid-synthesizing enzymes. Furthermore, similar changes in plasma bile acids and expression levels of bile acid transporters were detected in rats with UNX, a relatively mild animal model of renal dysfunction. These results suggest that changes in hepatic bile acid homeostasis are an early event in the progression of CRF, and increased plasma bile acid levels may result from an increased efflux of bile acids across the basolateral hepatocyte membrane (Fig. 6).

An important finding in this study was the increase in plasma bile acid concentrations in CRF, which is consistent with previous clinical reports by Jimenez et al. (14). Despite elevated bile acid levels, Cyp7a1, the rate-limiting de novo bile acid-synthesizing enzyme, was not repressed at either the mRNA level or the protein level. Another rate-limiting enzyme involved in the synthesis of cholic acid, Cyp8b1, also remained at normal levels. These results are in line with the absence of increased Shp mRNA expression in CRF rats, suggesting that Fxr was not activated. Furthermore, the expression of Fxr, which acts in concert with Shp to suppress bile acid-synthesizing enzymes, did not differ from the controls. Thus the contribution of the Fxr-Shp pathway to the increase in plasma bile acid levels appears to be minor, 
A

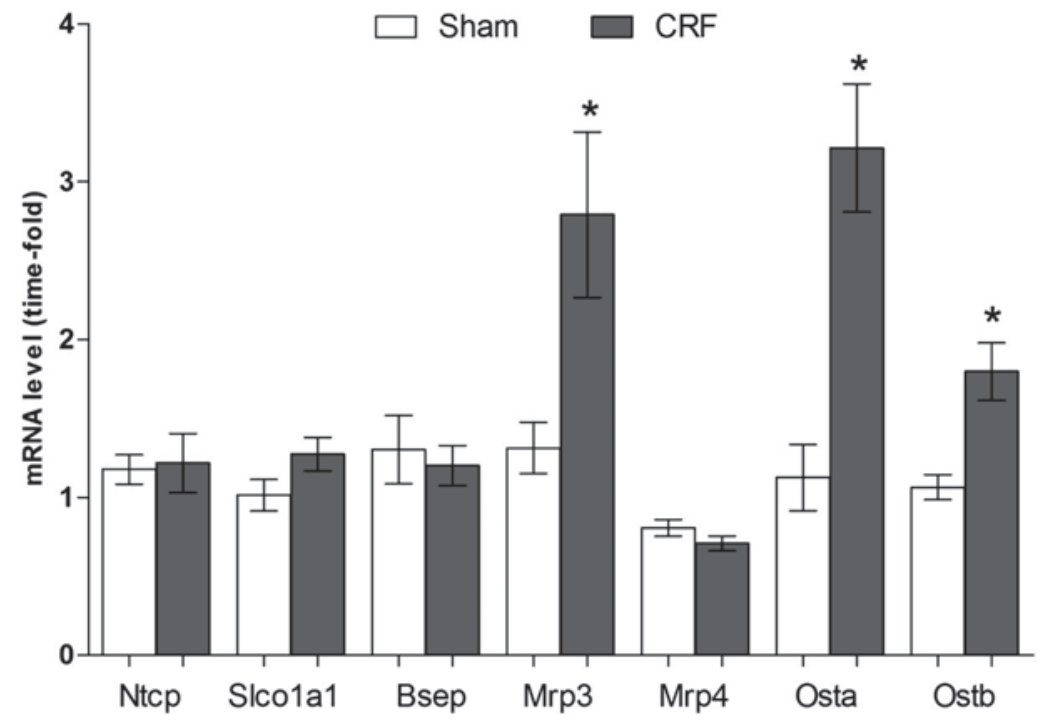

B

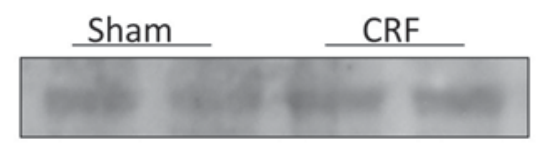

Ntcp

Slco1a1

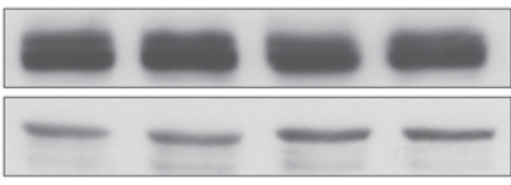

Mrp2

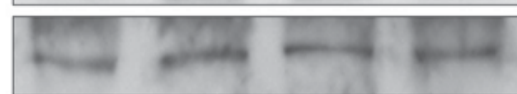

Mrp3

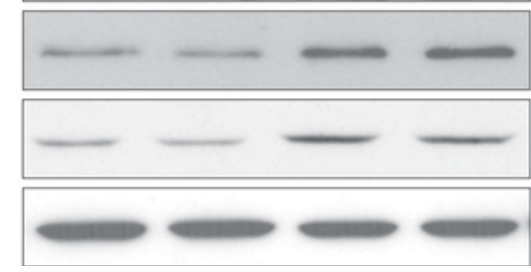

C

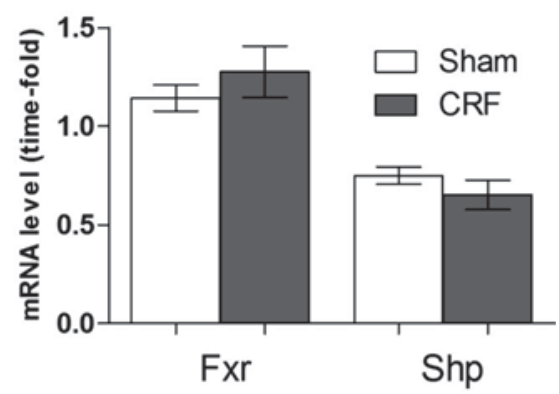

Osta

Actin
Fig. 2. Effect of CRF on the expression of bile acid transporters in the liver. A: comparison of hepatic bile acid transporter mRNA levels between sham and CRF groups. $B$ : representative Western blot of Bsep, Ntcp, Slco1a1, Mrp2, Mrp3, and Ost- $\alpha$ in liver tissue of sham and CRF groups. $C$ : comparison of hepatic Fxr and Shp mRNA levels between sham and CRF groups. Values are means $\pm \mathrm{SE} ; n=8$ /group. $* P \leq$ 0.01 . which also explains the lack of negative feedback regulation on de novo bile acid production. The increase in serum bile acids is most probably attributable to the increased expression of Ost- $\alpha / \beta$ and Mrp3. Normally, these genes are expressed at low levels in hepatocytes, and we hypothesize that their induction could shuttle the transport of bile acids back into sinusoidal blood (43). However, the extent to which induction of Ost- $\alpha / \beta$ and Mrp3 translates into a true increase in the basolateral efflux of bile acids remains to be elucidated in functional studies.

It is unclear whether the changes in bile acid transporter expression represent a secondary compensatory response to the changes in renal function induced by CRF or UNX. Increased plasma bile acid levels could activate energy expenditure in adipocytes and reduce macrophage inflammation and lipid loading through TGR5 $(28,29,38)$. As a result, the free fatty acids eluted from adipocytes may redistribute in organs such as the liver and kidneys $(40,41)$. Changed bile acid levels also reflect obese and diabetic conditions in both mice and humans $(4,18)$. The major efflux pump for bile acids out of the hepatocyte is the bile salt export pump (7), and induction of Bsep expression may reduce the bile acid load in hepa- tocytes. The increased expression of Mrp3, Ost- $\alpha$, and Ost- $\beta$ also provides a mechanism to lower hepatocellular retention of hydrophobic bile acids and other potentially toxic compounds that would normally be destined for biliary excretion. Other studies $(10,17)$ showed a significant increase in liver Mrp3 expression at the mRNA and protein levels in CRF rats, consistent with our results. Naud et al. (24) found a significant increase in liver Mrp2 at the mRNA but not the protein level in CRF rats, which is confirmed by our data.

Very few studies have evaluated the effect of CRF on the urinary output of bile acids. Clinical studies showed increased serum bile acids in both CRF and transplant patients; however, they did not show any change in the urinary output of bile acids in these patients (14). Data from Zollner et al. (43) suggest that the upregulation of Ost- $\alpha / \beta$ expression and the increased efflux of bile acids into the blood for renal excretion may exert a protective effect on hepatocytes and the biliary epithelium in response to an increased bile acid load (43). Moreover, recent studies demonstrate that uremic toxins can directly inhibit transport activities of organic anion transporters OATP1B1, OATP1B3, and OATP2B1 in hepatocytes $(31,33)$ and OATs 
$\mathbf{A}^{20}$

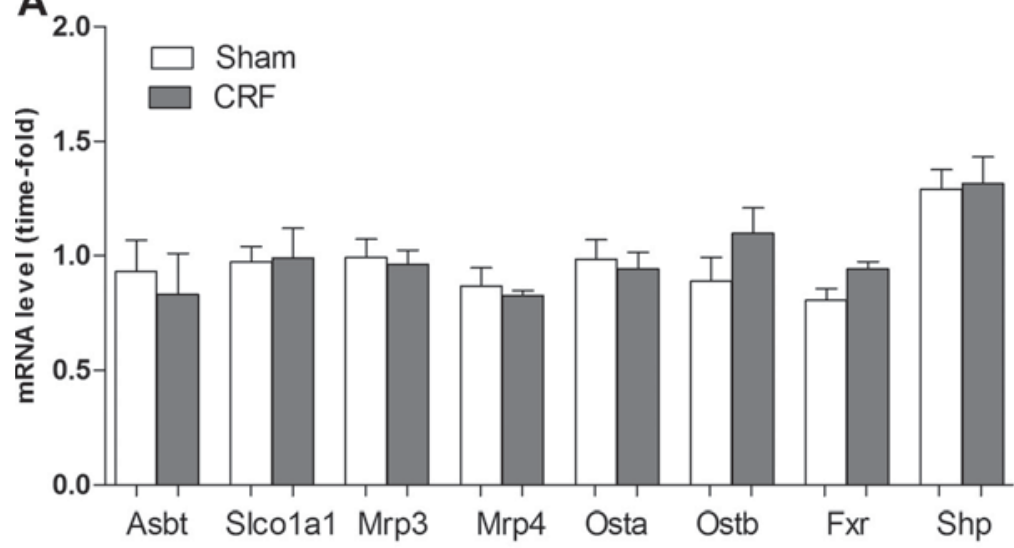

C

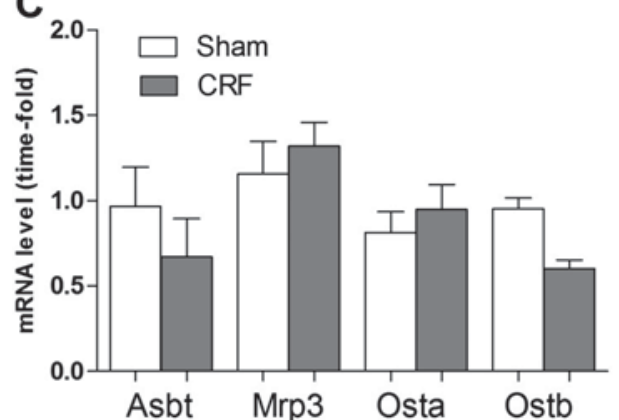

D
B

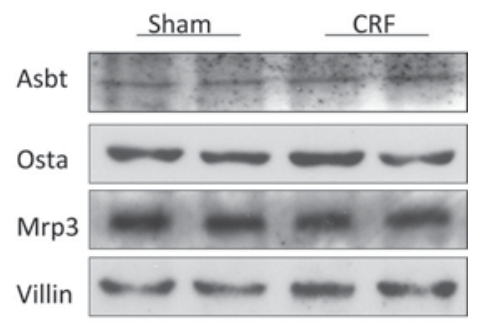

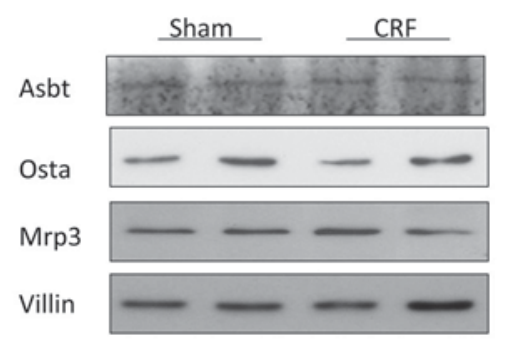

Fig. 3. Effect of CRF on the expression of bile acid transporters in the kidney and intestine. A: comparison of bile acid transporter mRNA levels in remnant kidneys of CRF rats and in kidneys from the sham group. Values are means \pm SE; $n=8$ /group. $B$ : representative Western blot of the apical Na ${ }^{+}$-dependent bile acid transporter (Asbt), Mrp3, and Ost- $\alpha$ in kidney tissue of sham and CRF groups. $C$ : comparison of bile acid transporter mRNA levels in ileum of sham and CRF rats. $D$ : representative Western blot of Asbt, Mrp3, and Ost- $\alpha$ in ileum tissue of sham and CRF groups. Values are means \pm SE; $n=8 /$ group. $* P \leq$ 0.01 .

in the kidney (13). However, further studies should be done to correlate renal expression of bile acid transporters with the urinary excretion of bile acids.

Previous studies demonstrated that cholic acid induces the expression of Ost- $\alpha$ and Ost- $\beta$ in the liver and kidneys in $\mathrm{Fxr}^{+/+}$but not $\mathrm{Fxr}^{-/-}$mice, confirming that Ost- $\alpha / \beta$ are regulated by Fxr (43). We observed similar changes in Ost- $\alpha$ and Ost- $\beta$ mRNA levels after Fxr activation in proximal tubule cells of rat kidney (Fig. 4). Nonetheless, in this study, the lack of parallelism in Ost- $\alpha / \beta$ expression between the liver and kidneys and the absence of Fxr activation in these two tissues suggest that the response of basolateral bile acid transporters is due to other factors. Recent evidence indicates that uremic toxins and proinflammatory cytokines may affect the transcription of hepatic transporter genes $(1,32)$. Naud et al. (24) showed that uremic serum modifies the expression of hepatic drug transporters including Mrp3. In human primary hepatocytes, TNF- $\alpha$, IL- 6 , and IL- $1 \beta$, the major proinflammatory cytokines that are increased in CRF, reduce the expression of NTCP and induce the expression of MRP1 and MRP4 (35). Moreover, several orphan nuclear receptors, including the pregnane $\mathrm{X}$ receptor and constitutive androstane receptor, are
Fig. 4. Effect of FXR agonists on the expression of bile acid transporters in primary cultured proximal tubule cells (PTCs) isolated from rat kidney. Shown is a comparison of bile acid transporter mRNA levels and Fxr and Shp mRNA levels in PTCs treated with DMSO, chenodeoxycholic acid (CDCA), or GW4064 for $24 \mathrm{~h}$. Values are means $\pm \mathrm{SE} ; n=3$ /group. $* P \leq 0.01$.

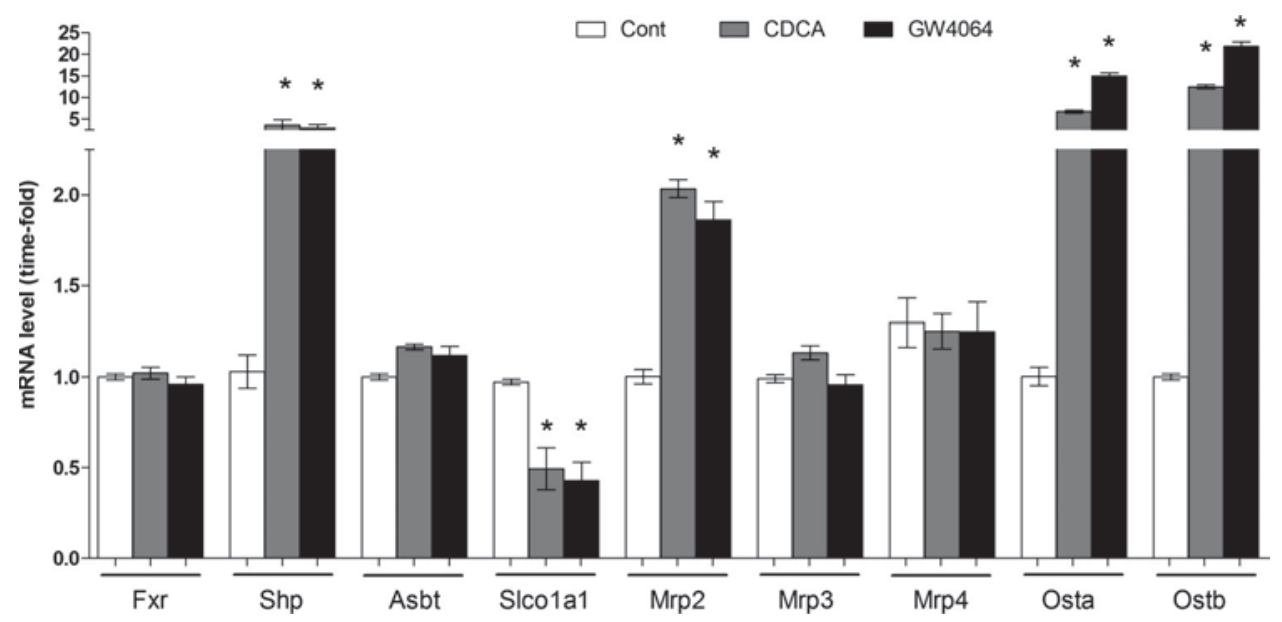


A
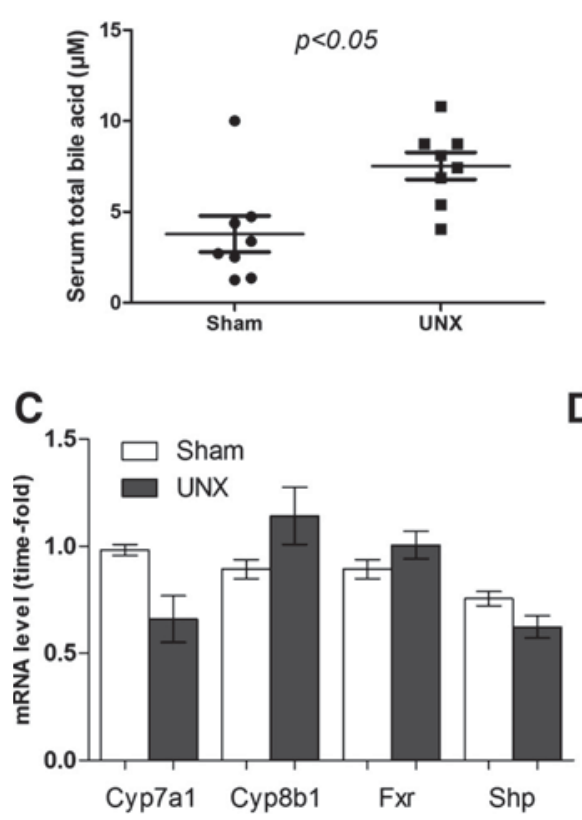

B

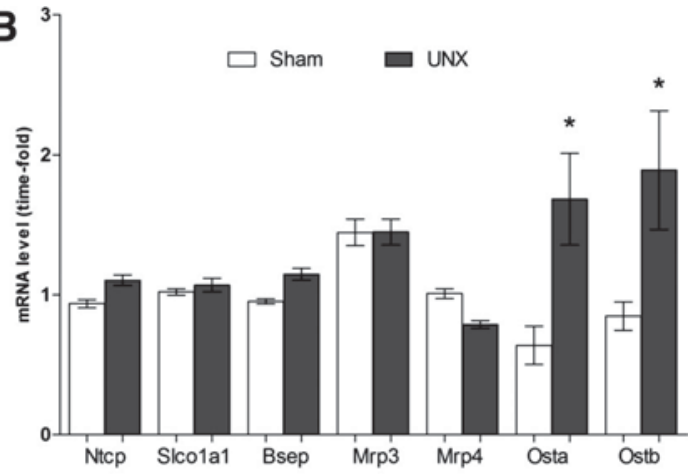

D

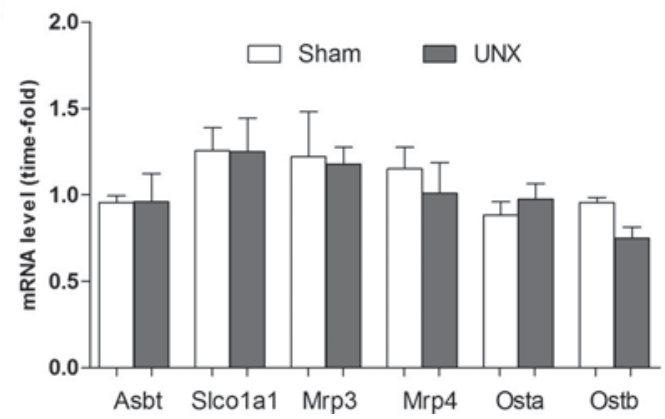

Fig. 5. Effect of uninephrectomy (UNX) on the expression of bile acid transporters in the liver and kidney. A: plasma total bile acid levels in sham-operated rats and rats with UNX. $B$ and $C$ : comparison of hepatic bile acid transporter mRNA levels and Cyp7a1, Cyp8b1, Fxr, and Shp mRNA levels between sham and UNX rats. $D$ : comparison of bile acid transporter mRNA levels in remnant kidneys of UNX rats and in kidneys of sham group. Values are means $\pm \mathrm{SE} ; n=$ 8/group. ${ }^{*} P \leq 0.01$ known to regulate the transcription of transporter genes in the liver of CRF rats $(2,20)$. However, the exact molecular mechanism for the increase in expression of Ost- $\alpha$ and Ost $\beta$ in CRF remains to be elucidated.

In summary, both CRF and uninephrectomy are associated with an increase in plasma bile acid levels, suggesting that this is an early event that takes place before kidney function is impaired. Maintenance of bile acid synthesis and elevated basolateral Mrp3 and Ost- $\alpha / \beta$ expression may either be a desired response during chronic renal disease to raise serum bile acid concentrations, thereby inducing a signaling effect of bile acids in other tissues, or it may indicate a protective mechanism of hepatocytes to facilitate basolateral extrusion of bile acids in response to an as yet uncharacterized effect of renal failure on hepatocyte bile acid homeostasis.

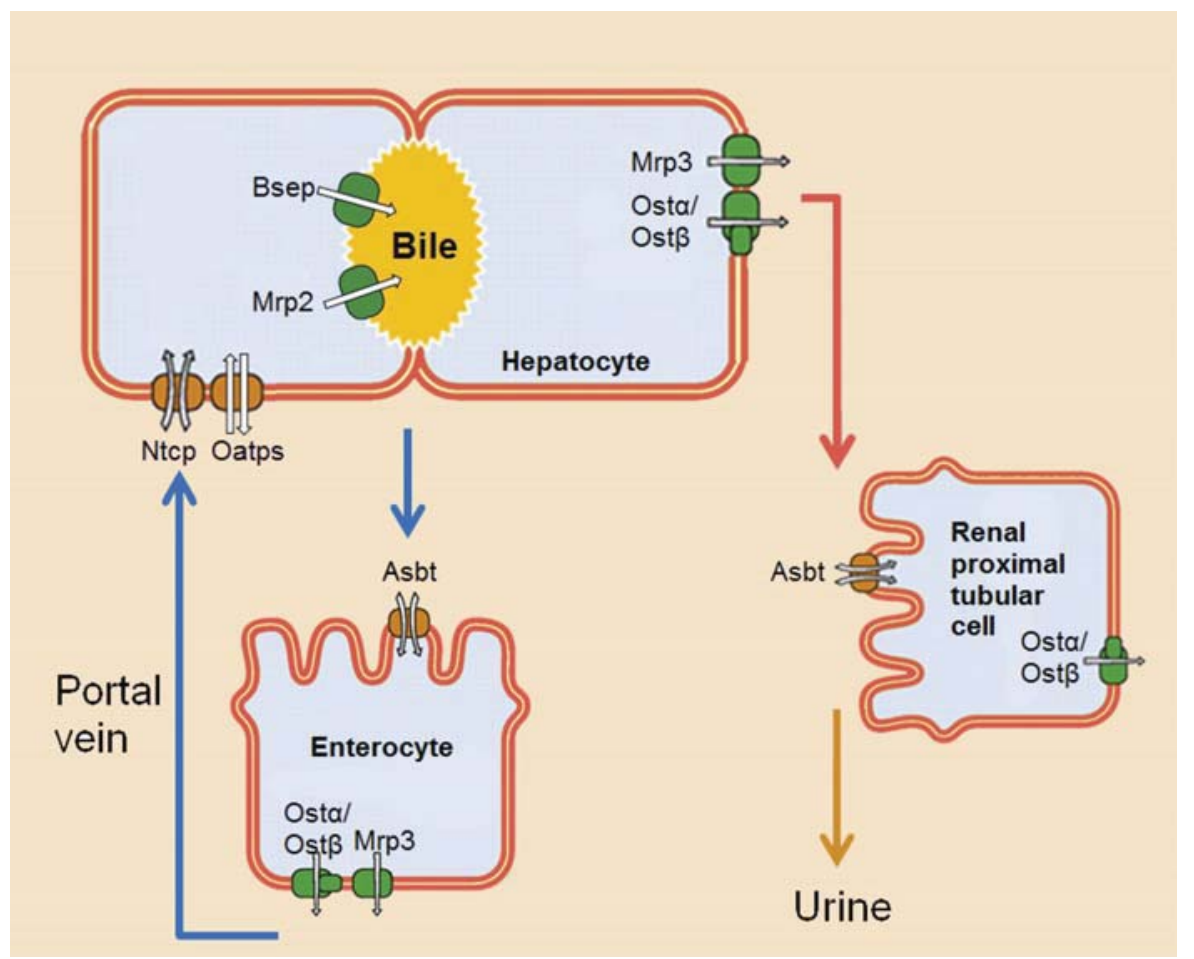

Fig. 6. Bile acid transporters expressed in the plasma membrane of hepatocytes, enterocytes, and renal proximal tubular cells. Transporters which efflux bile acids are shown in green, and transporters that mediate the uptake of bile acids are shown in orange. Bile acids are synthesized and conjugated in the liver and secreted into the intestine. They are reabsorbed into the portal circulation in the small intestine and subsequently return to the liver, where uptake into hepatocytes occurs by $\mathrm{Na}^{+}$-dependent (Ntcp) and $\mathrm{Na}^{+}$-independent (Oatps) transporters. In the kidney, bile acids undergo glomerular filtration, but are reabsorbed in the proximal renal tubule by the apical $\mathrm{Na}^{+}$-dependent bile acid transporter (Asbt). 


\section{GRANTS}

This study was supported by grant no. 320030_144193 from the Swiss National Science Foundation, the NCCR-Kidney.ch program, and the International Fellowship Program (grant no. 246539) on Integrative Kidney Physiology and Pathophysiology (IKPP).

\section{DISCLOSURES}

No conflicts of interest, financial or otherwise, are declared by the authors.

\section{AUTHOR CONTRIBUTIONS}

Author contributions: Z.G., L.C., C.H., D.A., and C.A.P. performed experiments; Z.G., L.C., C.H., C.A.P., and J.-P.M. analyzed data; Z.G. and G.A.K.-U. interpreted results of experiments; Z.G. and C.H. prepared figures; Z.G. drafted manuscript; Z.G., A.O., and G.A.K.-U. approved final version of manuscript; L.C., J.-P.M., A.O., and G.A.K.-U. edited and revised manuscript; G.A.K.-U. provided conception and design of research.

\section{REFERENCES}

1. Beigneux AP, Moser AH, Shigenaga JK, Grunfeld C, Feingold KR. Reduction in cytochrome P-450 enzyme expression is associated with repression of CAR (constitutive androstane receptor) and PXR (pregnane $\mathrm{X}$ receptor) in mouse liver during the acute phase response. Biochem Biophys Res Commun 293: 145-149, 2002.

2. Bohan A, Boyer JL. Mechanisms of hepatic transport of drugs: implications for cholestatic drug reactions. Semin Liver Dis 22: 123-136, 2002.

3. Boudville N, Prasad GV, Knoll G, Muirhead N, Thiessen-Philbrook H, Yang RC, Rosas-Arellano MP, Housawi A, Garg AX, and Donor Nephrectomy Outcomes Research (DONOR) Network. Meta-analysis: risk for hypertension in living kidney donors. Ann Intern Med 145: 185-196, 2006.

4. Chen X, Lou G, Meng Z, Huang W. TGR5: a novel target for weight maintenance and glucose metabolism. Exp Diabetes Res 2011: 853501, 2011.

5. Cheung AK, Wu LL, Kablitz C, Leypoldt JK. Atherogenic lipids and lipoproteins in hemodialysis patients. Am J Kidney Dis 22: 271-276, 1993.

6. Gai Z, Zhou G, Gui T, Itoh S, Oikawa K, Uetani K, Muragaki Y. Trps1 haploinsufficiency promotes renal fibrosis by increasing Arkadia expression. J Am Soc Nephrol 21: 1468-1476, 2010.

7. Gerloff T, Stieger B, Hagenbuch B, Madon J, Landmann L, Roth J, Hofmann AF, Meier PJ. The sister of P-glycoprotein represents the canalicular bile salt export pump of mammalian liver. J Biol Chem 273: 10046-10050, 1998.

8. Goodwin B, Jones SA, Price RR, Watson MA, McKee DD, Moore LB, Galardi C, Wilson JG, Lewis MC, Roth ME, Maloney PR, Willson TM, Kliewer SA. A regulatory cascade of the nuclear receptors FXR, SHP-1, and LRH-1 represses bile acid biosynthesis. Mol Cell 6: 517-526, 2000.

9. Gregg JA. Urinary excretion of bile acids in patients with obstructive jaundice and hepatocellular disease. Am J Clin Pathol 49: 404-409, 1968.

10. Holzer B, Stieger B, Folkers G, Meier PJ, Fattinger K. Differential regulation of basolateral and canalicular transporter expression in rat liver in chronic renal failure. Clin Pharmacol Ther 77: P34-P34, 2005.

11. Igel-Korcagova A, Raab P, Brensing KA, Poge U, Klehr HU, Igel M, von Bergmann K, Sudhop T. Cholesterol metabolism in patients with chronic renal failure on hemodialysis. J Nephrol 16: 850-854, 2003.

12. Javitt NB. Bile acid synthesis from cholesterol: regulatory and auxiliary pathways. FASEB J 8: 1308-1311, 1994.

13. Ji L, Masuda S, Saito H, Inui K. Down-regulation of rat organic cation transporter rOCT2 by 5/6 nephrectomy. Kidney Int 62: 514-524, 2002.

14. Jimenez F, Monte MJ, El-Mir MY, Pascual MJ, Marin JJ. Chronic renal failure-induced changes in serum and urine bile acid profiles. Dig Dis Sci 47: 2398-2406, 2002.

15. Kast HR, Goodwin B, Tarr PT, Jones SA, Anisfeld AM, Stoltz CM, Tontonoz P, Kliewer S, Willson TM, Edwards PA. Regulation of multidrug resistance-associated protein $2(\mathrm{ABCC} 2)$ by the nuclear receptors pregnane $\mathrm{X}$ receptor, farnesoid $\mathrm{X}$-activated receptor, and constitutive androstane receptor. J Biol Chem 277: 2908-2915, 2002.

16. Kida K, Nakajo S, Kamiya F, Toyama Y, Nishio T, Nakagawa $\mathbf{H}$. Renal net glucose release in vivo and its contribution to blood glucose in rats. J Clin Invest 62: 721-726, 1978.

17. Laouari D, Yang R, Veau C, Blanke I, Friedlander G. Two apical multidrug transporters, P-gp and MRP2, are differently altered in chronic renal failure. Am J Physiol Renal Physiol 280: F636-F645, 2001.
18. Li T, Francl JM, Boehme S, Ochoa A, Zhang Y, Klaassen CD, Erickson SK, Chiang JY. Glucose and insulin induction of bile acid synthesis: mechanisms and implication in diabetes and obesity. $\mathrm{J} \mathrm{Biol}$ Chem 287: 1861-1873, 2012.

19. Liang K, Vaziri ND. Gene expression of LDL receptor, HMG-CoA reductase, and cholesterol-7 alpha-hydroxylase in chronic renal failure. Nephrol Dial Transplant 12: 1381-1386, 1997.

20. Liddle C, Goodwin B. Regulation of hepatic drug metabolism: role of the nuclear receptors PXR and CAR. Semin Liver Dis 22: 115-122, 2002.

21. Mak RH, DeFronzo RA. Glucose and insulin metabolism in uremia. Nephron 61: 377-382, 1992.

22. McGuinness OP, Fugiwara T, Murrell S, Bracy D, Neal D, O'Connor D, Cherrington AD. Impact of chronic stress hormone infusion on hepatic carbohydrate metabolism in the conscious dog. Am J Physiol Endocrinol Metab 265: E314-E322, 1993.

23. Modica S, Gadaleta RM, Moschetta A. Deciphering the nuclear bile acid receptor FXR paradigm. Nucl Recept Signal 8: e005, 2010.

24. Naud J, Michaud J, Leblond FA, Lefrancois S, Bonnardeaux A, Pichette V. Effects of chronic renal failure on liver drug transporters. Drug Metab Dispos 36: 124-128, 2008.

25. Pandak WM, Li YC, Chiang JY, Studer EJ, Gurley EC, Heuman DM, Vlahcevic ZR, Hylemon PB. Regulation of cholesterol 7 alpha-hydroxylase mRNA and transcriptional activity by taurocholate and cholesterol in the chronic biliary diverted rat. J Biol Chem 266: 3416-3421, 1991.

26. Pandak WM, Vlahcevic ZR, Heuman DM, Krieg RJ, Hanna JD, Chan JC. Post-transcriptional regulation of 3-hydroxy-3-methylglutaryl coenzyme A reductase and cholesterol 7 alpha-hydroxylase in rats with subtotal nephrectomy. Kidney Int 46: 358-364, 1994.

27. Penno CA, Arsenijevic D, Da Cunha T, Kullak-Ublick GA, Montani JP, Odermatt A. Quantification of multiple bile acids in uninephrectomized rats using ultra-performance liquid chromatography-tandem mass spectrometry. Anal Methods 5: 1155-1164, 2013.

28. Pols TW, Nomura M, Harach T, Lo Sasso G, Oosterveer MH, Thomas C, Rizzo G, Gioiello A, Adorini L, Pellicciari R, Auwerx J, Schoonjans K. TGR5 activation inhibits atherosclerosis by reducing macrophage inflammation and lipid loading. Cell Metab 14: 747-757, 2011.

29. Pols TW, Noriega LG, Nomura M, Auwerx J, Schoonjans K. The bile acid membrane receptor TGR5 as an emerging target in metabolism and inflammation. J Hepatol 54: 1263-1272, 2011.

30. Stumvoll M, Chintalapudi U, Perriello G, Welle S, Gutierrez O, Gerich J. Uptake and release of glucose by the human kidney. Postabsorptive rates and responses to epinephrine. J Clin Invest 96: 2528-2533, 1995.

31. Sun H, Huang Y, Okochi H, Frassetto L, Benet LZ. Uremic toxins inhibit hepatic uptake of eprosartan (Abstract). Clin Pharmacol Ther 77: P2, 2005.

32. Toell A, Degenhardt S, Grabensee B, Carlberg C. Inhibitory effect of uremic solutions on protein-DNA-complex formation of the vitamin D receptor and other members of the nuclear receptor superfamily. $J$ Cell Biochem 74: 386-394, 1999.

33. Tsujimoto M, Hatozaki D, Shima D, Yokota H, Furukubo T, Izumi S, Yamakawa T, Minegaki T, Nishiguchi K. Influence of serum in hemodialysis patients on the expression of intestinal and hepatic transporters for the excretion of pravastatin. Ther Apher Dial 16: 580-587, 2012.

34. Vaziri ND, Sato T, Liang K. Molecular mechanisms of altered cholesterol metabolism in rats with spontaneous focal glomerulosclerosis. Kidney Int 63: 1756-1763, 2003.

35. Vee ML, Lecureur V, Stieger B, Fardel O. Regulation of drug transporter expression in human hepatocytes exposed to the proinflammatory cytokines tumor necrosis factor-alpha or interleukin-6. Drug Metab Dispos 37: 685-693, 2009.

36. Vlahcevic ZR, Pandak WM, Stravitz RT. Regulation of bile acid biosynthesis. Gastroenterol Clin North Am 28: 1-25, 1999.

37. Wagner M, Zollner G, Trauner M. Nuclear receptor regulation of the adaptive response of bile acid transporters in cholestasis. Semin Liver Dis 30: $160-177,2010$.

38. Watanabe M, Houten SM, Mataki C, Christoffolete MA, Kim BW, Sato H, Messaddeq N, Harney JW, Ezaki O, Kodama T, Schoonjans K, Bianco AC, Auwerx J. Bile acids induce energy expenditure by promoting intracellular thyroid hormone activation. Nature 439: 484-489, 2006.

39. Wilson FA, Treanor LL. Characterization of the passive and active transport mechanisms for bile acid uptake into rat isolated intestinal epithelial cells. Biochim Biophys Acta 406: 280-293, 1975. 
40. Zhao HL, Sui Y, Guan J, He L, Zhu X, Fan RR, Xu G, Kong AP, Ho CS, Lai FM, Rowlands DK, Chan JC, Tong PC. Fat redistribution and adipocyte transformation in uninephrectomized rats. Kidney Int 74: 467477, 2008.

41. Zhao HL, Sui Y, He L, Guan J, Xiao SJ, Zhong DR, Xu Q, Zeng SE. Lipid partitioning after uninephrectomy. Acta Diabetol 48: 317-328, 2011.

42. Zheng S, Huang Y, Yang L, Chen T, Xu J, Epstein PN. Uninephrectomy of diabetic OVE26 mice greatly accelerates albuminuria, fibrosis, inflammatory cell infiltration and changes in gene expression. Nephron Exp Nephrol 119: e21-e32, 2011.

43. Zollner G, Wagner M, Moustafa T, Fickert P, Silbert D, Gumhold J, Fuchsbichler A, Halilbasic E, Denk H, Marschall HU, Trauner M. Coordinated induction of bile acid detoxification and alternative elimination in mice: role of FXR-regulated organic solute transporter- $\alpha / \beta$ in the adaptive response to bile acids. Am J Physiol Gastrointest Liver Physiol 290: G923-G932, 2006. 